\title{
Sex as a Biologic Variable in Preclinical Imaging Research: Initial Observations with ${ }^{18}$ F-FLT
}

\author{
Szeman Ruby Chan ${ }^{1}$, Kelley Salem ${ }^{2}$, Justin Jeffery ${ }^{3}$, Ginny L. Powers ${ }^{2}$, Yongjun Yan $^{2,4}$, Kooresh I. Shoghi ${ }^{5}$, \\ Aparna M. Mahajan ${ }^{6}$, and Amy M. Fowler ${ }^{2-4}$ \\ ${ }^{1}$ Department of Pathology and Immunology, Washington University School of Medicine, St. Louis, Missouri; ${ }^{2}$ Department of \\ Radiology, University of Wisconsin School of Medicine and Public Health, Madison, Wisconsin; ${ }^{3}$ University of Wisconsin Carbone \\ Cancer Center, Madison, Wisconsin; ${ }^{4}$ Department of Medical Physics, University of Wisconsin School of Medicine and Public Health, \\ Madison, Wisconsin; ${ }^{5}$ Mallinckrodt Institute of Radiology, Washington University School of Medicine, St. Louis, Missouri; and \\ ${ }^{6}$ Department of Pathology and Laboratory Medicine, University of Wisconsin School of Medicine and Public Health, Madison, \\ Wisconsin
}

The study objective was to investigate whether sex influences $3^{\prime}-$ deoxy-3'-18F-fluorothymidine ( $\left.{ }^{18} \mathrm{~F}-\mathrm{FLT}\right)$ uptake and tissue distribution in mouse models of cancer. Methods: ${ }^{18} \mathrm{~F}-\mathrm{FLT}$ biodistribution was measured in 3 strains of male and female mice (129S6/SvEv, athymic nude, and BALB/c). ${ }^{18} \mathrm{~F}-\mathrm{FDG}$ biodistribution was measured for comparison. ${ }^{18} \mathrm{~F}-\mathrm{FLT}$ uptake was also measured in female 129S6/SvEv mice bearing estrogen-dependent SSM3 mouse mammary tumors, male athymic nude mice bearing androgendependent CWR22 prostate cancer xenografts, and male and female athymic nude mice bearing estrogen-independent MDAMB-231 human breast cancer xenografts. Ki-67 expression was assayed by immunohistochemistry. PET/CT imaging was performed to visualize ${ }^{18} \mathrm{~F}-\mathrm{FLT}$ biodistribution and to determine pharmacokinetics. Results: Greater ${ }^{18} \mathrm{~F}-\mathrm{FLT}$ activity was observed in blood, liver, muscle, heart, kidney, and bone in female than male mice. Pharmacokinetic analysis demonstrated higher early renal ${ }^{18} \mathrm{~F}-\mathrm{FLT}$ activity and greater accumulation of ${ }^{18} \mathrm{~F}-\mathrm{FLT}$ in the urinary bladder in male than female mice. The differential pattern of ${ }^{18} \mathrm{~F}$-FLT biodistribution between the sexes seen with ${ }^{18} \mathrm{~F}-\mathrm{FLT}$ was not observed with ${ }^{18} \mathrm{~F}-\mathrm{FDG}$. Increased tumoral ${ }^{18} \mathrm{~F}-\mathrm{FLT}$ uptake compared with muscle was observed in both the SSM3 mammary tumors $(2.4 \pm 0.17$ vs. $1.6 \pm$ 0.14 percentage injected dose [\%ID]/g at $2 \mathrm{~h}$ after injection, $P=$ $0.006)$ and the CWR22 prostate cancer xenografts $(0.34 \pm 0.08$ vs. $0.098 \pm 0.033 \% \mathrm{ID} / \mathrm{g}$ at $2 \mathrm{~h}$ after injection, $P=0.03$ ). However, because of higher nonspecific muscle uptake in female mice, tumor-to-muscle uptake ratios were greater for CWR22 tumors than for SSM3 tumors $(4.2 \pm 0.78$ vs. $1.5 \pm 0.049$ at $2 \mathrm{~h}$ after injection, $P=0.008$ ). Sex-dependent differences in ${ }^{18} \mathrm{~F}$-FLT uptake were also observed for MDA-MB-231 xenografts (tumor-to-muscle ratio, $7.2 \pm 0.9$ for female vs. $16.9 \pm 8.6$ for male, $P=0.039$ ). Conversely, greater tumoral Ki-67 staining was observed in female mice $(71 \% \pm$ $3 \%$ for female vs. $54 \% \pm 2 \%$ for male, $P=0.009$ ), and this finding more closely matched the relative differences in absolute ${ }^{18} \mathrm{~F}$-FLT tumor uptake values $(4.5 \pm 0.99 \% \mathrm{ID} / \mathrm{g}$ for female vs. $1.9 \pm 0.30$ $\% \mathrm{ID} / \mathrm{g}$ for male, $P=0.03)$. Conclusion: Depending on whether female or male mice are used, differences in biodistribution and nonspecific tissue uptake can adversely affect quantitative measures of ${ }^{18} \mathrm{~F}$-FLT uptake. Thus, sex is a potential variable to consider in

Received Aug. 10, 2017; revision accepted Nov. 13, 2017.

For correspondence or reprints contact: Amy M. Fowler, University of Wisconsin School of Medicine and Public Health, 600 Highland Ave., Madison, WI 53792.

E-mail: afowler@uwhealth.org

Published online Dec. 7, 2017.

COPYRIGHT (C) 2018 by the Society of Nuclear Medicine and Molecular Imaging. defining quantitative imaging metrics using ${ }^{18} \mathrm{~F}-\mathrm{FLT}$ to assess tumor proliferation.

Key Words: 3'-deoxy-3'-18F-fluorothymidine; cancer; sex differences; positron emission tomography; mice

J Nucl Med 2018; 59:833-838

DOI: 10.2967/jnumed.117.199406

A rising concern from the National Institutes of Health is the importance of including sex as a biologic variable in animal studies and human clinical trials (1). Women were not required to be included as subjects in clinical research until the Revitalization Act of 1993, and consideration of sex as an experimental variable did not extend to federally funded preclinical work until 2014. This policy is part of a broader goal to increase reproducibility and transparency between research studies and to ensure scientific rigor.

Oftentimes, the sex of cell lines is not considered in experimental design because the canonical thought was that, on the molecular level, basic cellular processes transcend sex differences. Although basic molecular mechanisms may be similar, male and female cells may respond differently to various stimuli. For example, it was shown that male neurons are more sensitive to oxidative stress than female neurons (2). Sex differences also extend to the organismal level, with sexual dimorphism identified in approximately $57 \%$ of phenotypes in mice (3). Thus, sex is an important biologic variable to consider in the design, analysis, and reporting of preclinical research. This concept is especially pertinent for understanding the pathophysiology and treatment of diseases that affect both sexes, such as many forms of cancer.

One of the hallmarks of cancer is abnormal sustained proliferation (4). As more therapies emerge and the field of precision medicine matures, imaging tools that can detect biologic changes before a change in anatomic tumor size occurs are becoming increasingly important. The most-studied radiopharmaceutical for in vivo imaging of cell proliferation is $3^{\prime}$-deoxy- $3^{\prime}-{ }^{18} \mathrm{~F}$-fluorothymidine $\left({ }^{18} \mathrm{~F}-\mathrm{FLT}\right)(5,6)$. It enters cells via membrane nucleoside transporters and undergoes phosphorylation by the cytosolic thymidine kinase- 1 enzyme as part of the thymidine salvage pathway of DNA synthesis during the S-phase of the cell cycle. 
Unlike endogenous thymidine, phosphorylated ${ }^{18}$ F-FLT does not incorporate into DNA, and because of a relatively slow rate of dephosphorylation, it accumulates intracellularly (7).

PET imaging using ${ }^{18} \mathrm{~F}$-FLT is being studied as a noninvasive method to measure the proliferative capacity of cancer and may provide an early indication of treatment response $(5,6)$. Although not yet approved by the U.S. Food and Drug Administration, ${ }^{18} \mathrm{~F}$-FLT has been studied through clinical trials in over 1,000 individuals and in patients with multiple cancer types (8). Biologic variables that can affect ${ }^{18} \mathrm{~F}$-FLT uptake include plasma thymidine levels; the expression level and functional activity of thymidine kinase-1, thymidylate synthase, and nucleoside transporters; and the overall balance of de novo versus salvage pathways of thymidine use (9). This study aimed to determine whether sex influences ${ }^{18} \mathrm{~F}$-FLT uptake and tissue biodistribution in preclinical oncology models.

\section{MATERIALS AND METHODS}

\section{Mice}

Athymic NCr-nu/nu mice were purchased from the Animal Production Program of the National Cancer Institute-Frederick National Laboratory for Cancer Research. BALB/c mice were also purchased from the National Cancer Institute. Male and female 129S6/SvEv mice were purchased from Taconic Farms, Inc.

\section{Cell Lines and Tumor Implantation}

Experiments were performed under an approved biosafety protocol. The human estrogen receptor-negative breast cancer cell line MDA-MB-231 was cultured at $37^{\circ} \mathrm{C}$ and $10 \% \mathrm{CO}_{2}$ in Dulbecco modified Eagle medium (Corning) with high glucose containing $10 \%$ fetal bovine serum (Corning) with penicillin and streptomycin (Gibco). SSM1 and SSM3 cell lines were isolated from primary spontaneous mammary adenocarcinomas in female transgenic STAT ${ }^{-1-}$ mice and were maintained in culture as described previously (10). The prostate cancer xenograft model, CWR22, was created from primary prostate carcinoma from a man with metastatic prostate cancer and was maintained in vivo via serial transplantation $(11,12)$. All cell lines were negative for murine pathogens and for Mycoplasma contamination, which can affect uptake of thymidine analogs (13). The MDA-MB-231 cell line was authenticated using short tandem repeat analysis.

Experiments were performed according to the guidelines of the American Association for Laboratory Animal Science under a protocol approved by the Animal Studies Committees in specific pathogen-free facilities accredited by the Association for Assessment and Accreditation of Laboratory Animal Care at Washington University School of Medicine and the University of WisconsinMadison. Mice aged 6-8 wk received a subcutaneous injection into the right thoracic mammary fat pad of $1 \times 10^{6}$ SSM1 or SSM3 cells in $100 \mu \mathrm{L}$ of phosphate-buffered saline or $2 \times 10^{6}$ MDA-MB-231 cells in $50 \%$ Matrigel (BD Biosciences) by volume. Tumor growth was monitored by palpation and measured in 2 perpendicular dimensions with calipers. Tumor volumes were calculated using the formula $a \times b^{2} / 2$, where $a$ is the long diameter and $b$ is the short diameter.

\section{Radiopharmaceuticals, PET/CT Imaging, and Tissue Biodistribution Assay}

${ }^{18} \mathrm{~F}$-FLT and ${ }^{18} \mathrm{~F}-\mathrm{FDG}$ were synthesized by the Cyclotron Facility at Washington University $(14,15) .{ }^{18} \mathrm{~F}$-FLT-specific activity at the end of synthesis ranged from 59 to $225 \mathrm{GBq} / \mu \mathrm{mol}(1,606-6,068$ $\mathrm{mCi} / \mu \mathrm{mol}) .{ }^{18} \mathrm{~F}-\mathrm{FLT}$ was also provided by the University of
Wisconsin-Madison Radiopharmaceutical Production Facility. Specific activity at the end of synthesis ranged from 333 to $629 \mathrm{GBq} / \mu \mathrm{mol}$ $(9,000-17,000 \mathrm{mCi} / \mu \mathrm{mol})$. Radiochemical purity was $100 \%$ for all preparations.

For PET/CT imaging, nonfasted mice were injected via the tail vein with approximately $0.93 \mathrm{MBq}(25 \mu \mathrm{Ci})$ of ${ }^{18} \mathrm{~F}$-FLT. The mice were not anesthetized during the radiotracer uptake period. Mice anesthetized with $1.5 \%-2.0 \%$ isoflurane were scanned supine in a small-animal PET/CT scanner (Inveon; Siemens Preclinical Solutions) $1 \mathrm{~h}$ after injection. CT images were acquired for approximately $12 \mathrm{~min}$, followed by PET images (40 million counts-typically less than $10 \mathrm{~min}$ ). One male and one female mouse were positioned side by side and imaged simultaneously for each scan. Images were analyzed using Inveon Research Workplace, version 3.0 (Siemens Medical Solutions USA, Inc.). The reconstruction method was 3-dimensional ordered-subset expectation maximization/maximum a posteriori with attenuation correction. Dynamic emission imaging began immediately after injection and continued for $60 \mathrm{~min}$ with the following time bins: $1 \times 3,6 \times 2,9 \times 5,6 \times 10,4 \times 30,2 \times 60,2 \times 120$, and $10 \times 300 \mathrm{~s}$. PET and CT images were automatically coregistered and adjusted if needed via visual alignment in all 3 planes. Regions of interest were manually drawn around the tumor and within the triceps muscle to determine nontarget tissue uptake using CT images for visual anatomic localization. Additional regions of interest were drawn around the kidneys, urinary bladder, bone (femur), liver, and heart for blood activity. Data are expressed as mean percentage injected dose (\%ID)/g. Tumor-to-muscle (T:M) ratio was calculated as the ratio of tumor $\% \mathrm{ID} / \mathrm{g}$ to muscle $\% \mathrm{ID} / \mathrm{g} .{ }^{18} \mathrm{~F}-\mathrm{FLT}$ clearance from the blood was calculated using a 1-phase exponential decay equation of the time-activity curve.

For biodistribution assays, tissues (blood, liver, muscle, heart, kidney, and whole bone) were harvested 1 or $2 \mathrm{~h}$ after tail vein injection of approximately $0.74-0.89 \mathrm{MBq}(20-24 \mu \mathrm{Ci})$ of ${ }^{18} \mathrm{~F}-\mathrm{FLT}$ or $0.74 \mathrm{MBq}$ $(20 \mu \mathrm{Ci})$ of ${ }^{18} \mathrm{~F}-\mathrm{FDG}$ in nonfasted mice. Radioactivity was measured using a $\gamma$-counter (2480 Wizard $^{2}$; Perkin Elmer) and decaycorrected to calculate $\% \mathrm{ID} / \mathrm{g}$. To minimize differences due to variations in ${ }^{18} \mathrm{~F}$-FLT preparations, the same batch of ${ }^{18} \mathrm{~F}$-FLT was used for experimentation within the same strains of male and female mice.

\section{Tissue Histology}

Sections of formalin-fixed paraffin-embedded mammary tumors were deparaffinized and rehydrated followed by antigen retrieval in citrate buffer (pH 6) and stained for Ki-67 (VP-K452, 1:800; Vector Laboratories, Inc.). Positive signal was developed using SignalStain IHC Detection Reagent (horseradish peroxidase, mouse; Cell Signaling Technology) followed by diaminobenzidine chromogen. Hematoxylin and eosin staining was also performed. A whole-slide bright-field imaging system (Aperio Image Scope software; Leica Biosystems) was used to scan slides at $\times 40$ magnification. The percentage of tumor cells staining positively for Ki-67 was visually scored by a pathologist with subspecialty training in breast pathology and $4 \mathrm{y}$ of experience.

\section{Statistical Analyses}

Results are presented as mean \pm SE unless indicated otherwise. Two-way ANOVA with a Sídák posttest was used to determine significance between male and female mice for biodistribution assays. The Mann-Whitney test was used to determine the statistical significance between control and experimental groups. The paired $t$ test was used to compare across different time points within the same group of animals. All tests are 2-sided, with a $P$ value of 0.05 or less considered significant. Analyses were performed using Prism, version 6.05 (GraphPad Software). 


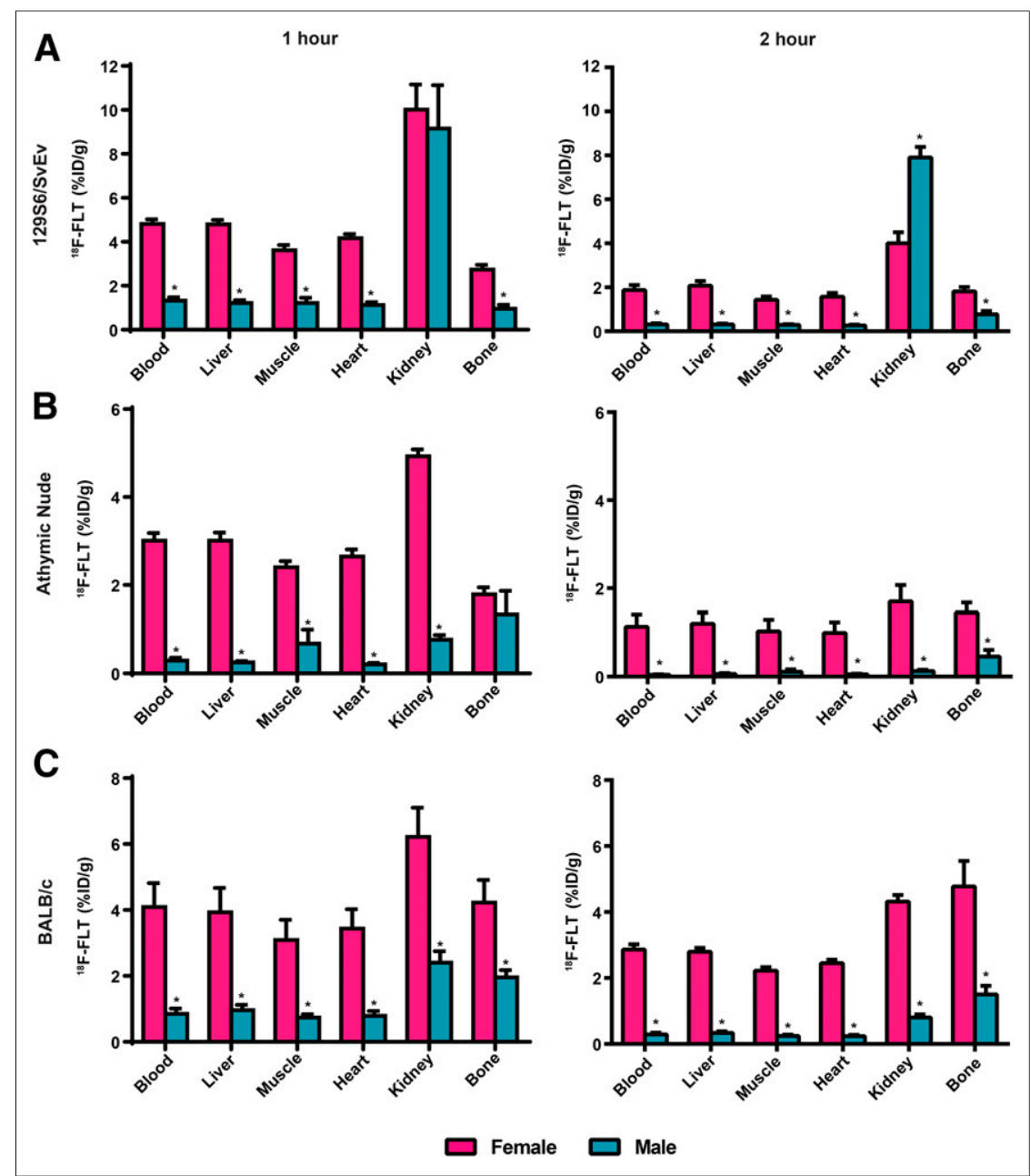

FIGURE 1. ${ }^{18} \mathrm{~F}-\mathrm{FLT}$ biodistribution (\%ID/g) in male and female $129 \mathrm{~S} 6 / \mathrm{SvEv}(\mathrm{A})$, athymic nude (B), and BALB/c (C) mice sacrificed 1 and $2 \mathrm{~h}$ after injection of $0.74-0.89 \mathrm{MBq}(20-24 \mu \mathrm{Ci})$ of ${ }^{18} \mathrm{~F}-$ FLT ( $n=5129 S 6 / S v E v, 5$ athymic nude, and 4 BALB/c mice per time point). ${ }^{\star} P<0.05$ (male vs. female for each tissue).

\section{RESULTS}

\section{${ }^{18} \mathrm{~F}-\mathrm{FLT}$ Tissue Biodistribution in Female Versus Male Mice}

To determine whether sex is a potential biologic variable for ${ }^{18}$ F-FLT uptake in preclinical models of cancer, we performed tissue biodistribution experiments using 3 different mouse strains, 129S6/SvEv, athymic nude, and BALB/c (Fig. 1). ${ }^{18}$ F-FLT activity was higher at 1 and $2 \mathrm{~h}$ after injection in the blood, liver, muscle, heart, and bone in female than male 129S6/SvEv mice (Fig. 1A). At $1 \mathrm{~h}$, there was similar renal accumulation of ${ }^{18} \mathrm{~F}$-FLT in both sexes. At $2 \mathrm{~h},{ }^{18} \mathrm{~F}-\mathrm{FLT}$ activity in the kidneys was less in female than male mice. For athymic nude mice, ${ }^{18} \mathrm{~F}$-FLT uptake was greater in female than male mice for all tissues measured, with the exception of bone at $1 \mathrm{~h}$, which was not significantly different (Fig. 1B). The third mouse strain tested, BALB/c, showed ${ }^{18}$ F-FLT uptake significantly higher in all female than male organs (Fig. 1C). Sex-dependent differences in ${ }^{18}$ F-FLT tissue biodistribution were accentuated when results were normalized to mouse weight (Supplemental Fig. 1; supplemental materials are available at http://jnm.snmjournals.org). Thus, we observed that ${ }^{18} \mathrm{~F}$-FLT uptake in the blood, liver, muscle, heart, and bone was higher in female than male mice across all 3 mouse strains.
To test whether these differences in tissue biodistribution could be visualized with PET imaging, we chose female and male athymic nude mice as a representative strain to undergo PET/CT. Female mice had greater overall visual ${ }^{18} \mathrm{~F}$-FLT signal than male mice, with the exception of the kidneys and urinary bladder, which appeared similar (Fig. 2). Therefore, PET/ CT is sensitive enough to detect sex differences in ${ }^{18} \mathrm{~F}$-FLT biodistribution and further confirmed our data obtained via $\gamma$-counting of excised tissues.

\section{Dynamic ${ }^{18} \mathrm{~F}-\mathrm{FLT}$ PET/CT Imaging in Female Versus Male Mice}

To investigate ${ }^{18}$ F-FLT pharmacokinetics in male and female mice, we performed dynamic PET/CT imaging of athymic nude mice at multiple time points during the first hour after injection (Fig. 3). Time-activity curves demonstrated that ${ }^{18} \mathrm{~F}$-FLT activity in the urinary bladder was higher in male than female mice at all time points (Fig. 3A). Male mice also had a greater spike in renal ${ }^{18}$ F-FLT uptake during the first 1-2 min after injection (Fig. 3B). For blood (Fig. 3C), liver (Fig. 3D), bone (Fig. 3E), and muscle (Fig. 3F), the time-activity curves appeared similar in male and female mice at early time points. The half-life of ${ }^{18} \mathrm{~F}$-FLT in blood was $0.36 \mathrm{~min}$ (95\% confidence interval, 0.29-0.47) for male mice and $0.20 \mathrm{~min}$ (95\% confidence interval, $0.15-0.30$ ) for female mice. However, the curves tended to diverge at around $30 \mathrm{~min}$ after injection, and by $60 \mathrm{~min}$ the activity in these tissues was higher in female than male mice. These data suggest that there is a difference in the physiologic processing of ${ }^{18}$ F-FLT during the first $30 \mathrm{~min}$ after injection.

\section{${ }^{18}$ F-FDG Tissue Biodistribution in Female Versus Male Mice}

To determine whether sex variability is specific to ${ }^{18} \mathrm{~F}-\mathrm{FLT}$, we tested a more commonly used ${ }^{18} \mathrm{~F}$-labeled radiopharmaceutical, ${ }^{18} \mathrm{~F}-\mathrm{FDG}$, for imaging glucose metabolism. A tissue biodistribution assay was performed on male and female $129 \mathrm{~S} 6 / \mathrm{SvEv}$ mice 1 and $2 \mathrm{~h}$ after injection using the same dose of ${ }^{18} \mathrm{~F}-\mathrm{FDG}$ as was used previously for ${ }^{18} \mathrm{~F}$ FLT (Fig. 4). The only significant difference in ${ }^{18} \mathrm{~F}-\mathrm{FDG}$ tissue uptake was in the heart, with greater uptake in female

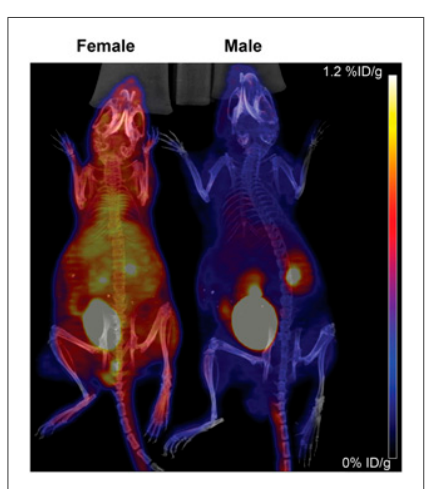

FIGURE 2. ${ }^{18} \mathrm{~F}-\mathrm{FLT}$ PET/CT maximal-intensity-projection images of representative female $(n=3)$ and male $(n=3)$ athymic nude mice scanned concurrently $1 \mathrm{~h}$ after injection of $0.93 \mathrm{MBq}(25 \mu \mathrm{Ci})$ of ${ }^{18} \mathrm{~F}-\mathrm{FLT}$. 


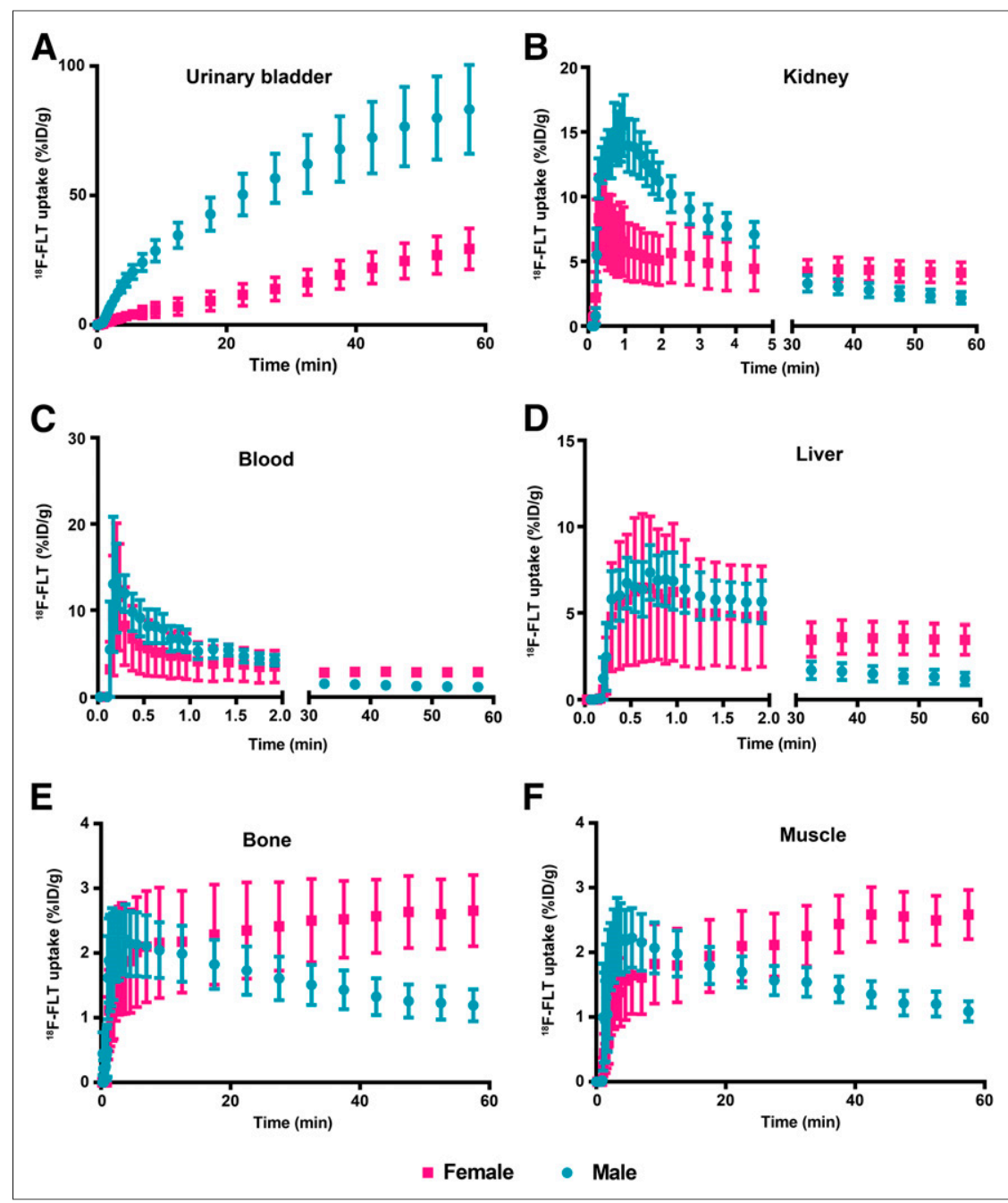

FIGURE 3. Time-activity curves for ${ }^{18} \mathrm{~F}-\mathrm{FLT}$ in male and female athymic nude mice imaged using dynamic PET from 0 to $60 \mathrm{~min}$ after injection of approximately $0.93 \mathrm{MBq}(25 \mu \mathrm{Ci})$ of ${ }^{18} \mathrm{~F}$ FLT. Regions of interest were drawn, and time-activity curves determined, for urinary bladder (A), kidney $(B)$, blood $(C)$, liver $(D)$, bone $(E)$, and muscle $(F)$.

than male mice at both time points. Thus, with this exception, differential sex-dependent tissue biodistribution may be specific to ${ }^{18} \mathrm{~F}$-FLT and may not pertain to all ${ }^{18} \mathrm{~F}$-labeled molecular imaging agents.

\section{${ }^{18}$ F-FLT Uptake by Estrogen-Dependent Mouse Mammary Tumors Versus Androgen-Dependent Prostate Cancer Xenografts}

We tested the potential impact of the sex-based physiologic differences in ${ }^{18}$ F-FLT biodistribution and kinetics on the imaging of proliferation in the hormone-dependent tumor models. We used estrogen receptor-positive SSM3 tumors as a representative estrogendependent mammary tumor model grown in female mice and CWR22 tumors as a representative androgen-dependent prostate tumor model in which tumoral ${ }^{18} \mathrm{~F}$-FLT uptake can be reduced by androgen ablation in male mice (16). SSM3 and CWR22 tumors were similar in size (mean $\pm \mathrm{SD}, 488 \pm 494 \mathrm{~mm}^{3}$ and $272 \pm$ $192 \mathrm{~mm}^{3}$, respectively; $P=0.21$ ) at the time of assay. Tumor uptake of ${ }^{18} \mathrm{~F}$-FLT was measured at 1 and $2 \mathrm{~h}$ after injection using tissue biodistribution assays. There was statistically significant higher ${ }^{18}$ F-FLT uptake in tumor than in muscle both for the SSM3 tumors $(4.3 \pm 0.27$ vs. $3.2 \pm 0.25 \% \mathrm{ID} / \mathrm{g}$ at $1 \mathrm{~h}, P=0.02 ; 2.4 \pm 0.17$ vs. $1.6 \pm 0.14$ $\% \mathrm{ID} / \mathrm{g}$ at $2 \mathrm{~h}, P=0.006)$ and for the CWR22 xenografts $(0.86 \pm 0.06$ vs. 0.41 $\pm 0.07 \% \mathrm{ID} / \mathrm{g}$ at $1 \mathrm{~h}, P=0.004 ; 0.34 \pm$ 0.08 vs. $0.098 \pm 0.033 \% \mathrm{ID} / \mathrm{g}$ at $2 \mathrm{~h}, P=$ $0.03)$. However, because of higher nonspecific muscle uptake in female mice, T:M ratios were greater for CWR22 xenografts than for SSM3 tumors at both 1 and $2 \mathrm{~h}$ after injection $(P=0.03$ and 0.0083 , respectively) (Fig. 5). The highest T:M ratio for the CWR22 xenografts occurred at $2 \mathrm{~h}$ after injection and was $4.2 \pm 0.78$. The highest T:M ratio for the SSM3 tumors occurred at $2 \mathrm{~h}$ after injection and was only $1.5 \pm 0.05$. As a result, CWR22 xenografts display more tumor-specific uptake of ${ }^{18} \mathrm{~F}-\mathrm{FLT}$ based on their higher T:M ratios, whereas SSM3 tumors exhibit higher absolute values of ${ }^{18} \mathrm{~F}$-FLT uptake along with higher nonspecific muscle uptake. Another mouse mammary carcinoma cell line (SSM1) showed biodistribution results similar to those of the SSM3 tumors grown in female 129S6/SvEv mice (Supplemental Fig. 2).

\section{${ }^{18}$ F-FLT Uptake by Hormone- Independent Human Breast Cancer Xenografts in Female Versus Male Mice}

The mouse-derived SSM3 tumors require estrogen for tumor growth and were grown in female immunocompetent mice. The human-derived CWR22 tumors depend on androgens for tumor growth and were grown in male immunocompromised mice. Thus, we chose to directly compare the ${ }^{18}$ F-FLT uptake of a hormone-independent breast cancer cell line that can be grown as xenografts in either female or male mice. MDA-MB-231 cells were grown as tumor xenografts in athymic nude female and male mice. The mice were injected with ${ }^{18} \mathrm{~F}$-FLT and, $2 \mathrm{~h}$ later, sacrificed. Tissue was then harvested and counted for radioactivity. Tumor volumes were $499 \pm 143 \mathrm{~mm}^{3}$ (mean \pm SD) in the female mice and $352 \pm 104 \mathrm{~mm}^{3}$ in the male mice at the time of the biodistribution experiment $(P=0.05)$. Both female and male mice had greater ${ }^{18} \mathrm{~F}$-FLT uptake in MDA-MB-231 tumors than in muscle (female mice: $4.5 \pm 0.99 \% \mathrm{ID} / \mathrm{g}$ for tumor vs. $0.67 \pm 0.18$ $\% \mathrm{ID} / \mathrm{g}$ for muscle, $P=0.005$; male mice: $1.9 \pm 0.30 \% \mathrm{ID} / \mathrm{g}$ for tumor vs. $0.16 \pm 0.07 \% \mathrm{ID} / \mathrm{g}$ for muscle, $P=0.0004$ ) (Fig. 6A). However, female mice also had more nonspecific muscle uptake than male mice $(0.67 \pm 0.18 \% \mathrm{ID} / \mathrm{g}$ vs. $0.16 \pm 0.07 \% \mathrm{ID} / \mathrm{g}, P=$ 0.0275). This disparity resulted in a lower T:M ratio for female than male mice $(7.2 \pm 0.9$ vs. $16.9 \pm 8.6, P=0.039)$.

To determine whether absolute tumor uptake $(\% \mathrm{ID} / \mathrm{g})$ or T:M ratio better reflects proliferation, tumor $\mathrm{Ki}-67$ staining was performed on MDA-MB-231 tumors grown in female and male mice. A greater percentage of Ki-67-positive staining was observed in female than male tumors $(71 \% \pm 3 \%$ vs. $54 \% \pm 2 \%$; $P=0.009$ ) (Fig. 6B). 


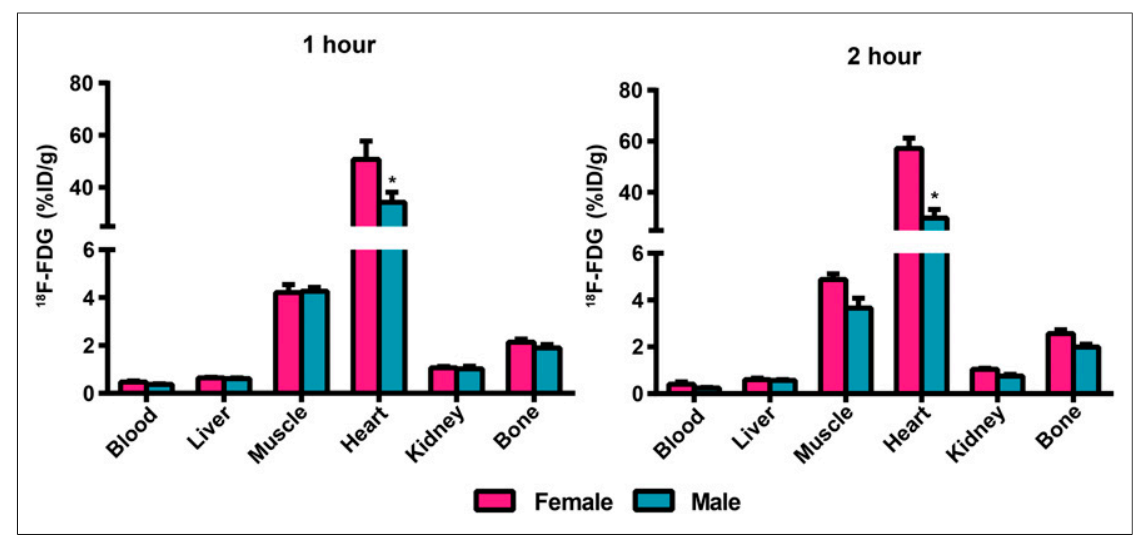

FIGURE 4. ${ }^{18} \mathrm{~F}-\mathrm{FDG}$ biodistribution (\%ID/g) in male and female $129 \mathrm{~S} 6 / \mathrm{SvEv}$ mice sacrificed 1 and $2 \mathrm{~h}$ after injection of $0.74 \mathrm{MBq}(20 \mu \mathrm{Ci})$ of ${ }^{18} \mathrm{~F}-\mathrm{FDG}\left(n=5\right.$ per group). ${ }^{*} P<0.05$ (male vs. female for each tissue).

\section{DISCUSSION}

The purpose of this study was to investigate whether sex is a potential biologic variable in preclinical studies of ${ }^{18} \mathrm{~F}-\mathrm{FLT}$ PET imaging. We demonstrated that female mice have an overall greater ${ }^{18}$ F-FLT uptake than male mice in multiple tissues. We also observed higher ${ }^{18} \mathrm{~F}-\mathrm{FLT}$ activity in the kidney at early time points and greater accumulation of ${ }^{18} \mathrm{~F}$-FLT in the urinary bladder at all time points in male than female mice, suggesting sex-dependent differences in renal clearance. For the 2 hormone-dependent tumor models, differences in ${ }^{18} \mathrm{~F}$ FLT biodistribution between the sexes resulted in altered interpretation of proliferative status on imaging, depending on whether absolute tumor uptake $(\% \mathrm{ID} / \mathrm{g})$ or T:M ratio was used as the method of quantification. On images of the MDA-MB-231 xenograft (the hormone-independent breast cancer xenograft capable of being grown in both male and female mice), distinct patterns of ${ }^{18} \mathrm{~F}$-FLT uptake were observed depending on the sex of the mouse. Furthermore, quantification of ${ }^{18}$ F-FLT uptake as absolute tumor uptake $(\% \mathrm{ID} / \mathrm{g})$ better approximated the Ki-67 proliferative index than did T:M ratios. This work demonstrates that sex is an important consideration in defining quantitative imaging metrics using ${ }^{18} \mathrm{~F}-\mathrm{FLT}$ as a noninvasive measure of tumor proliferation.

To the best of our knowledge, sex-dependent differences in ${ }^{18} \mathrm{~F}$ FLT biodistribution and PET imaging of preclinical models have

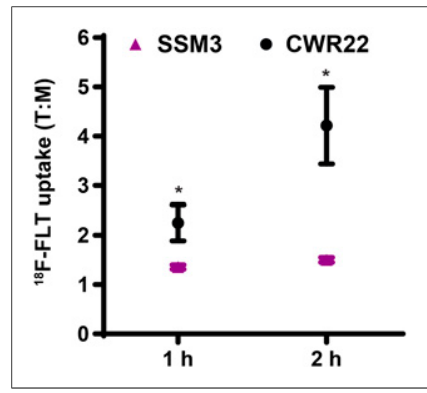

FIGURE 5. ${ }^{18} \mathrm{~F}-\mathrm{FLT}$ biodistribution (T:M \%ID/g) in SSM3 mammary tumor-bearing and CWR22 prostate cancer xenograft-bearing mice sacrificed $1 \mathrm{~h}(n=5 \mathrm{SSM} 3$ and 4 CWR22) and $2 \mathrm{~h}(n=5$ SSM 3 and 5 CWR22) after injection of $0.85 \mathrm{MBq}$ $(23 \mu \mathrm{Ci})$ of ${ }^{18} \mathrm{~F}-\mathrm{FLT}$. ${ }^{*} P<0.05$ (CWR22 vs. SSM3 tumors). not been previously reported. In a systematic review of 174 primary publications using ${ }^{18} \mathrm{~F}$ FLT for oncologic imaging, factors influencing ${ }^{18} \mathrm{~F}$-FLT uptake in tumors were identified (9). The reviewed studies used tumor models grown in only male or female mice and lacked a direct comparison of ${ }^{18} \mathrm{~F}$ FLT imaging between the sexes. Similarly, a comprehensive review of preclinical studies comparing ${ }^{18} \mathrm{~F}-\mathrm{FDG}$ and ${ }^{18} \mathrm{~F}$ FLT PET imaging for tumorresponse monitoring lacked information on whether any differences between the sexes were investigated (17).
Our results add to a small, but growing, amount of literature determining how sex may affect preclinical imaging research. Some evidence points to differences due to the pharmacokinetic properties of the imaging agent, such as absorption, distribution, metabolism, and excretion. For example, sex differences in the metabolism and distribution of the opioid receptor ligand $N$-(3- ${ }^{18}$ F-fluoropropyl)- $N$-nordiprenorphine in rats have been reported (18). Other evidence reflects the underlying sex-dependent differences in the expression level of the binding target or receptor of the imaging agent. In research using an ${ }^{11} \mathrm{C}$-labeled PET radioligand for imaging sphingosine-1-phosphate receptor 2 in a mouse model of multiple sclerosis, differences in cerebellar tracer uptake between male and female mice were identified, reflecting the underlying sex-dependent difference in receptor protein expression $(19,20)$. Sex differences were also reported in $\sigma_{2^{-}}$ receptor binding density in the brain of a transgenic mouse model of Alzheimer disease using a $\sigma_{2}$-receptor-specific imaging agent (21).

There are comparatively more reports on sex differences in clinical imaging research, particularly for neurologic and cardiac imaging. For example, several studies have reported sex differences in regional brain glucose metabolism using ${ }^{18} \mathrm{~F}-\mathrm{FDG}$ PET and neuroreceptor imaging with targeted radioligands for opioid, dopamine, and cannabinoid receptors (22-25). Sex differences in cardiac glucose metabolism have also been demonstrated using ${ }^{18} \mathrm{~F}-\mathrm{FDG}$ PET/CT in healthy men and women (26).

This study had several limitations. First, this initial report included only a few breast and prostate cancer models. Subsequent work using additional cell lines will establish the generalizability of the results. In addition to sex, age is another potential biologic variable in preclinical studies (27). Although our results show sex differences in ${ }^{18}$ F-FLT biodistribution using only one age group (6-8 wk) for xenograft studies, results may differ in older mice used for transgenic or spontaneous tumor models. Last, our results may not translate to humans because of species-level pharmacokinetic differences. In humans, ${ }^{18} \mathrm{~F}$ FLT undergoes hepatic metabolism via glucuronidation
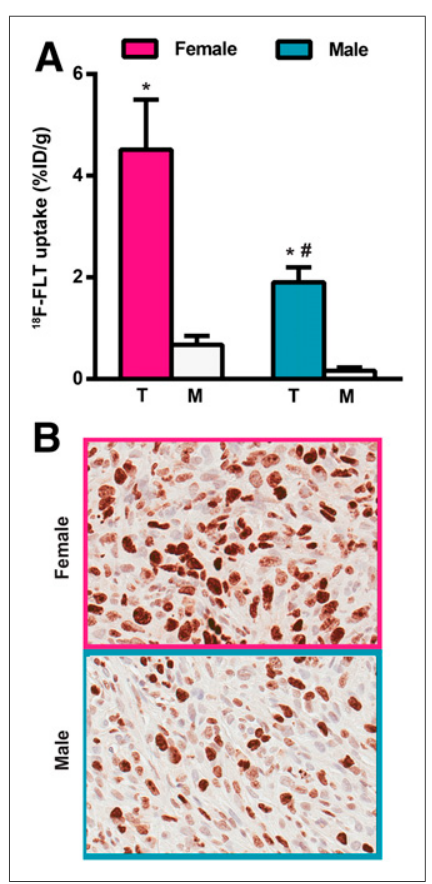

FIGURE 6. (A) ${ }^{18} \mathrm{~F}-\mathrm{FLT}$ biodistribution (tumor $[\mathrm{T}$ ] and muscle [M] $\% \mathrm{ID} / \mathrm{g})$ in female $(n=5)$ and male $(n=5)$ mice bearing hormone-independent, estrogen receptor-negative MDA-MB-231 human breast cancer cells and sacrificed $2 \mathrm{~h}$ after injection of $0.67-0.78 \mathrm{MBq}(18-21 \mu \mathrm{Ci})$ of ${ }^{18} \mathrm{~F}-\mathrm{FLT} .{ }^{*} P<0.05$ (tumor vs. muscle). \#P<0.05 (female tumor vs. male tumor). (B) Representative Ki-67 immunohistochemistry of MDAMB-231 tumors $(\times 40)$. 
(28), but in mice, ${ }^{18} \mathrm{~F}-\mathrm{FLT}$ is excreted mainly by the kidneys in its original form $(29,30)$. Furthermore, plasma thymidine levels have been shown to be 320 -fold higher in rodents than in humans (31).

\section{CONCLUSION}

Our results demonstrate that sex is an important variable to consider for preclinical imaging using ${ }^{18} \mathrm{~F}$-FLT. Sex-dependent differences in ${ }^{18} \mathrm{~F}$-FLT biodistribution and nonspecific tissue uptake can adversely affect quantitative measures of ${ }^{18}$ F-FLT uptake, as well as conclusions on relative tumor proliferation status in comparison with ex vivo reference standards, such as Ki-67 staining. These results have broader implications, as the National Cancer Institute and the imaging community have embarked on numerous initiatives to define imaging metrics of response to therapy. Thus, standardization between the sexes to yield sexindependent imaging metrics of tumor phenotype and therapy response is critical to advance the translational utility of molecular imaging.

\section{DISCLOSURE}

This work was supported by grants from the NCI (U01CA141541-01) and the Mallinckrodt Institute of Radiology at Washington University (MIR 11-037). Kooresh Shoghi is supported by grants U24CA209837 and U54CA199092 from the NCI. Funding was also provided to Amy Fowler through the University of Wisconsin Institute of Clinical and Translational Research KL2 Scholar Award (KL2TR000428). Facilities and services were provided by the University of Wisconsin Carbone Cancer Center (UWCCC) Small Animal Imaging Facility, Experimental Pathology Laboratory, and the Translational Research Initiatives in Pathology Laboratory (P30 CA014520). No other potential conflict of interest relevant to this article was reported.

\section{ACKNOWLEDGMENTS}

We thank Dr. John Katzenellenbogen for thoughtful discussions and critical reading of the manuscript; Nicole Fettig and the staff of the Washington University Pre-Clinical Imaging Facility for excellent technical assistance; the Washington University Cyclotron Facility and Carmen Dence for expertise in ${ }^{18}$ F-FLT radiosynthesis; and the University of Wisconsin-Madison Cyclotron Laboratory for ${ }^{18} \mathrm{~F}$ production.

\section{REFERENCES}

1. Clayton JA, Collins FS. Policy: NIH to balance sex in cell and animal studies. Nature. 2014;509:282-283.

2. Du L, Bayir H, Lai $\mathrm{Y}$, et al. Innate gender-based proclivity in response to cytotoxicity and programmed cell death pathway. J Biol Chem. 2004;279: 38563-38570.

3. Karp NA, Mason J, Beaudet AL, et al. Prevalence of sexual dimorphism in mammalian phenotypic traits. Nat Commun. 2017;8:15475.

4. Hanahan D, Weinberg RA. Hallmarks of cancer: the next generation. Cell. 2011;144:646-674.

5. Bollineni VR, Kramer GM, Jansma EP, Liu Y, Oyen WJ. A systematic review on $\left[{ }^{18} \mathrm{~F}\right] \mathrm{FLT}-\mathrm{PET}$ uptake as a measure of treatment response in cancer patients. Eur J Cancer. 2016;55:81-97.

6. Tehrani OS, Shields AF. PET imaging of proliferation with pyrimidines. J Nucl Med. 2013;54:903-912.

7. Grierson JR, Schwartz JL, Muzi M, Jordan R, Krohn KA. Metabolism of 3'deoxy-3'-[F-18]fluorothymidine in proliferating A549 cells: validations for positron emission tomography. Nucl Med Biol. 2004;31:829-837.
8. Investigator's brochure for $3^{\prime}$-deoxy-3'-[F-18] fluorothymidine: [F-18]FLT: an investigational positron emission tomography (PET) radiopharmaceutical for injection intended for use as an in vivo diagnostic for imaging active cellular proliferation of malignant tumors. American College of Radiology Imaging Network website. https://www.acrin.org/portals/0/protocols/6688/flt_ib_final_v5-52011.pdf. Published May 11, 2011. Accessed January 22, 2018.

9. Schelhaas S, Heinzmann K, Bollineni VR, et al. Preclinical applications of 3'deoxy- $3^{\prime}-\left[{ }^{18} \mathrm{~F}\right]$ fluorothymidine in oncology: a systematic review. Theranostics. 2017;7:40-50.

10. Chan SR, Vermi W, Luo J, et al. STAT1-deficient mice spontaneously develop estrogen receptor alpha-positive luminal mammary carcinomas. Breast Cancer Res. 2012;14:R16.

11. Wainstein MA, He F, Robinson D, et al. CWR22: androgen-dependent xenograft model derived from a primary human prostatic carcinoma. Cancer Res. 1994;54: 6049-6052.

12. Pretlow TG, Wolman SR, Micale MA, et al. Xenografts of primary human prostatic carcinoma. J Natl Cancer Inst. 1993;85:394-398.

13. Sinigaglia F, Talmadge KW. Inhibition of $\left[{ }^{3} \mathrm{H}\right]$ thymidine incorporation by Mycoplasma arginini-infected cells due to enzymatic cleavage of the nucleoside. Eur J Immunol. 1985;15:692-696.

14. Suehiro M, Vallabhajosula S, Goldsmith SJ, Ballon DJ. Investigation of the role of the base in the synthesis of [ ${ }^{18}$ F]FLT. Appl Radiat Isot. 2007;65:1350-1358.

15. Yun M, Oh SJ, Ha HJ, Ryu JS, Moon DH. High radiochemical yield synthesis of $3^{\prime}$-deoxy-3'-[ ${ }^{18}$ F]fluorothymidine using (5'-O-dimethoxytrityl-2' - deoxy- $3^{\prime}$-O-nosylbeta-D-threo pentofuranosyl)thymine and its 3-N-BOC-protected analogue as a labeling precursor. Nucl Med Biol. 2003;30:151-157.

16. Oyama N, Ponde DE, Dence C, Kim J, Tai YC, Welch MJ. Monitoring of therapy in androgen-dependent prostate tumor model by measuring tumor proliferation. J Nucl Med. 2004;45:519-525.

17. Jensen MM, Kjaer A. Monitoring of anti-cancer treatment with ${ }^{18} \mathrm{~F}-\mathrm{FDG}$ and ${ }^{18}$ F-FLT PET: a comprehensive review of pre-clinical studies. Am J Nucl Med Mol Imaging. 2015;5:431-456.

18. Chesis PL, Griffeth LK, Mathias CJ, Welch MJ. Sex-dependent differences in $\mathrm{N}$-(3-[ $\left.{ }^{18} \mathrm{~F}\right]$ fluoropropyl)-N-nordiprenorphine biodistribution and metabolism. $J$ Nucl Med. 1990;31:192-201.

19. Yue X, Jin H, Liu H, Rosenberg AJ, Klein RS, Tu Z. A potent and selective C-11 labeled PET tracer for imaging sphingosine-1-phosphate receptor 2 in the CNS demonstrates sexually dimorphic expression. Org Biomol Chem. 2015;13:7928-7939.

20. Cruz-Orengo L, Daniels BP, Dorsey D, et al. Enhanced sphingosine-1-phosphate receptor 2 expression underlies female CNS autoimmunity susceptibility. J Clin Invest. 2014;124:2571-2584.

21. Sahlholm K, Liao F, Holtzman DM, Xu J, Mach RH. Sigma-2 receptor binding is decreased in female, but not male, APP/PS1 mice. Biochem Biophys Res Commun. 2015;460:439-445.

22. $\mathrm{Hu} \mathrm{Y}, \mathrm{Xu} \mathrm{Q}, \mathrm{Li} \mathrm{K}$, et al. Gender differences of brain glucose metabolic networks revealed by FDG-PET: evidence from a large cohort of 400 young adults. PLoS One. 2013;8:e83821.

23. Zubieta JK, Dannals RF, Frost JJ. Gender and age influences on human brain muopioid receptor binding measured by PET. Am J Psychiatry. 1999;156:842-848.

24. Okita K, Petersen N, Robertson CL, Dean AC, Mandelkern MA, London ED. Sex differences in midbrain dopamine D2-type receptor availability and association with nicotine dependence. Neuropsychopharmacology. 2016;41:2913-2919.

25. Normandin MD, Zheng MQ, Lin KS, et al. Imaging the cannabinoid CB1 receptor in humans with $\left[{ }^{11} \mathrm{C}\right] \mathrm{OMAR}$ : assessment of kinetic analysis methods, test-retest reproducibility, and gender differences. J Cereb Blood Flow Metab. 2015;35:1313-1322.

26. Kakinuma Y, Okada S, Nogami M, Kumon Y. The human female heart incorporates glucose more efficiently than the male heart. Int J Cardiol. 2013;168: 2518-2521.

27. Jackson SJ, Andrews N, Ball D, et al. Does age matter? The impact of rodent age on study outcomes. Lab Anim. 2017;51:160-169.

28. Shields AF, Briston DA, Chandupatla S, et al. A simplified analysis of $\left[{ }^{18} \mathrm{~F}\right] 3^{\prime}-$ deoxy-3'-fluorothymidine metabolism and retention. Eur J Nucl Med Mol Imaging. 2005;32:1269-1275.

29. Kim SJ, Lee JS, Im KC, et al. Kinetic modeling of $3^{\prime}$-deoxy-3'-18 F-fluorothymidine for quantitative cell proliferation imaging in subcutaneous tumor models in mice. J Nucl Med. 2008;49:2057-2066.

30. Barthel H, Cleij MC, Collingridge DR, et al. $3^{\prime}$-deoxy $-3^{\prime}-\left[{ }^{18} \mathrm{~F}\right]$ fluorothymidine as a new marker for monitoring tumor response to antiproliferative therapy in vivo with positron emission tomography. Cancer Res. 2003;63:3791-3798.

31. Li KM, Clarke SM, Rivory LP. Quantitation of plasma thymidine by highperformance liquid chromatography-atmospheric pressure chemical ionization mass spectrometry and its application to pharmadynamic studies in cancer patients. Anal Chim Acta. 2003;486:51-61. 